\title{
金属窒化物の表面エネルギーに関する第一原理解析
}

\author{
中西亮 太 $^{\mathrm{a}}$ \\ a 岡山県工業技術センター 研究開発部 ( ⿳ 701-1296 岡山県岡山市北区芳賀 5301)
}

\section{Surface Energy of Metal Nitrides Analyzed by First Principles Calculation}

\section{Ryota NAKANISHI ${ }^{\text {a }}$}

${ }^{a}$ Department of Research and Development, Industrial Technology Center of Okayama Prefecture (5301, Haga, Kita-ku, Okayama-shi Okayama 701-1296)

Keywords : First Principles Calculation, Surface Energy, Metal Nitride

\section{1. はじめに}

現在, 超微細加工によるナノ構造体の作製において, 原子 や分子スケールで表面や界面の平坦性ならびに構造を制御す る必要が生じている。それゆえ, 原子や分子スケールでの表 面と界面の解析が必要となっている。しかし, 原子や分子は 分光技術で用いられる光の波長より小さいため, 実験的解析 は困難である。そこで, 原子や分子スケールで制御が必要な 材料表面において, 計算機シミュレーションの重要性が認識 され始めている。

本論文では，材料を原子や電子の集合体として扱う分子シ ミュレーション法を紹介したうえで, 金型コーティング膜の 離型性予測を目的として, 第一原理計算を用いて金属窒化物 の表面エネルギーを計算した内容を紹介する。

\section{2. 材料開発における計算機シミュレーション}

\section{1 計算機シミュレーションについて}

現在, 材料開発において計算機シミュレーションは欠かせ ないツールとなっている。これにより, 材料のスケールに応 じた物性の予測が可能となりつつある。本節では, 材料を原 子や電子の集合体として扱う分子シミュレーション法につい て，その特徴を説明する。

分子シミュレーション法は古典的分子動力学法, モンテカ ルロ法, 第一原理計算法に大別される。古典的分子動力学法は, 多原子系における個々の原子の動きについて運動方程式を解 くことにより, 系の静的, 動的過程を求める方法である ${ }^{1)}$ 。 温度や圧力を考慮した計算が可能という特徴を有する。有限 要素法で取り扱うことのできない原子レベルの変形・破壊現 象を計算することができる。しかし, 経験的ポテンシャル関 数が必要であることや計算量が澎大となる欠点もある。本計 算法を用いて, 充填ゴムの力学特性に関する研究 ${ }^{2)}$ や $\mathrm{Al}$ およ び $\mathrm{Cu}$ ナノ結晶中の欠陥構造に関する研究 ${ }^{3)}$ などが報告されて いる。

次にモンテカルロ法は, 乱数を用いたシミュレーションを
繰り返すことにより, 実現可能性の高い状態を推定する計算 法である ${ }^{4)}$ 。特に, 結晶成長のシミュレーションに適用され ることが多い。たとえば, $100 \times 100$ 原子あるいはそれ以上 の大きい表面上で, 原子が積み重なって薄膜を形成する過程 を再現できる。本計算法を用いて, Si (100) 表面上に形成し たナノメートル程度の島の崩壊過程の研究がなされている ${ }^{5)}$ 。 しかし, 実験パラメータが必要であることや原子の動きを連 続的に追跡できないという久点がある。

最後に第一原理計算法であるが，この手法は実験パラメー 夕を用いることなく, 量子力学や固体物理を基礎として非経 験的に, 電子・原子レベルにおける固体の電子状態や物性を 求めることが可能な手法である ${ }^{6)}$ 。

古典的分子動力学法およびモンテカルロ法は, いずれも材 料定数あるいは実験パラメータを必要とする。このため, 金 属や金属窒化物, 半導体などの物性を研究するためには十分 でない計算方法である。これに対し，第一原理計算法は材料 定数や実験パラメータが不要であることから, これらの研究 には有効な手法と考えられる。次節では第一原理計算法につ いてより詳しく説明する。

\section{2 第一原理計算の概要}

第一原理計算法は, 新しい材料や構造に対して, 実験を行

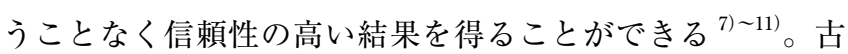
典的分子動力学法やモンテカルロ法と比較して計算量が増加 するものの, これらの手法を適用することが難しい(1) 異種 材料界面や欠陥, 表面の特性評価や，(2) 新機能を有する素 材や材料の組合せの探索などに用いられている。

密度沉関数理論 ${ }^{12), 13)}$ に基づく第一原理計算では, 系の全 エネルギーが電子密度の沉関数として表されることを用いて, 基底状態の波動関数を数值的に求める。また，スピン分極を 考慮した計算も可能である。系が $N$ 個の電子を含むとき, スピン分極を考慮しない場合には式(1)と (2)で示すコーン シャム方程式 ${ }^{12), 14)}$ を解くことになる。

$$
\left[-\frac{\hbar^{2} \nabla^{2}}{2 m}+v_{e x t}(r)+\int \frac{2 n\left(r^{\prime}\right)}{\left|r-r^{\prime}\right|} d r^{\prime}+\frac{\delta E_{x c}[n(r)]}{\delta n(r)}\right] \phi_{i}(r)=\varepsilon_{i} \phi_{i}(r)(1)
$$




$$
n(r)=\sum_{i}^{N}\left|\phi_{i}(r)\right|^{2}
$$

$$
\left(\phi_{i}(i=1,2, \cdots N) \text { は } \varepsilon_{1} \leq \varepsilon_{2} \leq \varepsilon_{3} \leq \cdots \leq \varepsilon_{N} \text { の順番 }\right)
$$

ここで, 式(1)の左辺第 1 項は電子の運動エネルギー, 第 2 項は原子核と電子の相互作用エネルギー, 第 3 項は電子間の 相互作用エネルギー，第 4 項は交換相関エネルギーである。 また， $\phi_{i}$ と $\varepsilon_{i}$ は $i$ 番目のコーンシャム軌道とエネルギー固有 值である。

ここで，交換相関エネルギーを

$$
E_{x c}\left[n_{+}(r), n_{-}(r)\right]=\int \varepsilon_{x c}\left[n_{+}(r), n_{-}(r)\right] n(r) d r .
$$

なお，スピン分極を考慮する場合には，＋スピン， - スピ ンの電子密度をそれぞれ $n_{+}(r), n_{-}(r)$ とすると $\left(n(\mathrm{r})=n_{+}(r)\right.$ $\left.+n_{-}(r)\right)$, 式 (3) 中の交換相関エネルギーは $n_{+}(r)+n_{-}(r)$ の 関数となる。

これに伴い，コーンシャム方程式は次式のように書き換え られる。

$$
\begin{aligned}
& {\left[-\frac{\hbar^{2} \nabla^{2}}{2 m}+v_{e x t}(r)+\int \frac{2 n\left(r^{\prime}\right)}{\left|r-r^{\prime}\right|} d r^{\prime}+\frac{\delta E_{x c}\left[n_{+}(r), n_{-}(r)\right]}{\delta n_{+}(r)}\right] \phi_{i \sigma}(r)} \\
& =\varepsilon_{i \sigma} \phi_{i \sigma}(r) \\
& n_{\sigma}(r)=\sum\left|\phi_{i \sigma}(r)\right|^{2}
\end{aligned}
$$

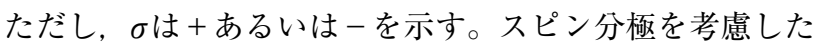
場合には, 考慮しない場合の 2 倍の連立方程式を解くことに なる。

波動関数が求まれば, 系の全エネルギーや原子に働く力, 応力などを得ることができる。

\section{3． $\mathrm{NaCl}$ 型金属窒化物の表面物性}

これまでに金型コーティング膜に関して，皮膜の密着性や機 械的特性に関する実験的な研究が多数報告されている ${ }^{15) ~ 23) 。 ~}$ また，第一原理計算を用いて，弾性定数を求めることで，高 硬度な膜を探索する研究も報告されている ${ }^{24,25)}$ 。一方, 金型 コーティング膜の離型性については, 面粗度の向上, 硬質ク ロムめっき処理の耐食性・耐摩耗性の改善, フッ素樹脂コー ティングやマイクロショットピーニングなどの実験結果が報 告されている ${ }^{26), 27)}$ 。しかし，これらの表面改質を施しても， 金型表面の耐熱性・耐摩耗性や表面性状の改善が必要である とともに，離型性の飛躍的な向上は実現していない ${ }^{28) ~ 30) 。 ~}$

金型の離型性が劣る場合，成形不良や成形の中断が起こり， 生産に悪影響を及ぼす。金型の離型性を確保するために，一 般的には油など液体の離型剤を型に噴霧する。しかし，離型 剂を用いると成形後の洗浄 ${ }^{31), 32)}$ が必要となることや, 離型 剤の噴霧による環境悪化が問題となる。また, 薬剤や食器に ついては, 離型剤が使用できない場合もある。それゆえ, 離 型性に優れた金型コーティング膜を開発することは，洗浄時 間の短縮や金型寿命の向上をもたらす点で価值が高い。

金型コーティング膜の離型性を理解するためには，成形物

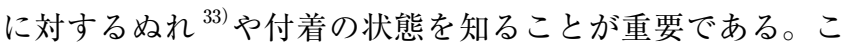
れらの現象は金型コーティング膜の表面エネルギーに支配さ れていると考えられる。そこで，金型コーティング膜に用い
られる金属窒化物の表面エネルギーに関する文献を調査した 結果，これらの実験值は未報告であることがわかった。なお， 第一原理計算法により, TiN (100)と (110)の表面エネルギー として $1.75 \mathrm{~J} / \mathrm{m}^{2}$ と $3.13 \mathrm{~J} / \mathrm{m}^{2}$ の值が報告されている ${ }^{34)}$ 。また, $\mathrm{TiN}$ 各結晶面の表面エネルギーについて, (111) > (110) > (100)の大小関係の結果が報告されている ${ }^{34)}$ 。しかし，TiN 以外の第一原理計算については報告が見当たらない。

そこで，本節では第一原理計算法を用い, $\mathrm{NaCl}$ 型金属窒 化物の表面エネルギーを計算した。具体的な計算内容は次の 通りである。まず, $\mathrm{NaCl}$ 型構造を有する TiN, $\mathrm{VN}, \mathrm{CrN}$, $\mathrm{ZrN}, \mathrm{TaN}, \mathrm{NbN}$ の金属窒化物の格子定数を計算し, 実験值 と比較した。この 6 種類を計算対象としたのは, これらの金 属窒化物が成膜可能なためである。次に, TiN (100) と (110) の表面エネルギーを計算し, 報告されている計算值と比較し た。さらに, 表面緩和や不純物の吸着がない理想的な表面に ついて, TiN, VN, $\mathrm{CrN}, \mathrm{ZrN}, \mathrm{TaN}, \mathrm{NbN}$ の表面エネルギー を計算した。

\section{3. $1 \mathrm{NaCl}$ 型金属窒化物の安定構造}

本計算では, 密度沉関数法 ${ }^{13)}$ に基づく局所密度近似と擬 ポテンシャル法を用いた第一原理計算を行った。使用したプ ログラムパッケージはアクセルリス社製の CASTEP ${ }^{35)}$ である。 まず， $\mathrm{NaCl}$ 型構造を有する金属窒化物について構造最適化 を行った。図 1 に $\mathrm{NaCl}$ 型構造の慣用単位胞の計算セルを示 す。セル内の原子数は 8 個である。図 1 において, 黒球が金 属原子を，白球が $\mathrm{N}$ 原子を表している。

表 1 に金属窒化物の格子定数の計算值を示す。比較のため, 実験値 ${ }^{36) ~ 41)}$ および実験值と計算值の差も示してある。これ より，本計算により得られた $\mathrm{TiN}, \mathrm{ZrN}, \mathrm{VN}, \mathrm{NbN}$ の格子 定数は, 文献值と $1 \%$ 以内の差で一致していることがわかる。 また， $\mathrm{CrN}$ と TaN の格子定数は文献值とややずれが大きい ものの, 高々 $2.8 \%$ 程度の差で一致している。

\section{3. $2 \mathrm{NaCl}$ 型金属窒化物の表面エネルギー}

TiN， VN， CrN， ZrN，TaN， NbN (100)と(110)の表面エ

表 1 金属窒化物における格子定数の計算值と実験值の比較

\begin{tabular}{ccccccc}
\hline & $\mathrm{TiN}$ & $\mathrm{VN}$ & $\mathrm{CrN}$ & $\mathrm{ZrN}$ & $\mathrm{TaN}$ & $\mathrm{NbN}$ \\
\hline 計算値 $(\AA)$ & 4.26 & 4.12 & 4.04 & 4.58 & 4.41 & 4.41 \\
\hline 実験値 $(\AA)$ & 4.24 & 4.13 & 4.15 & 4.58 & 4.34 & 4.41 \\
\hline 計算値と実験值の差 $(\%)$ & 0.47 & -0.24 & -2.65 & 0 & 1.61 & 0 \\
\hline
\end{tabular}

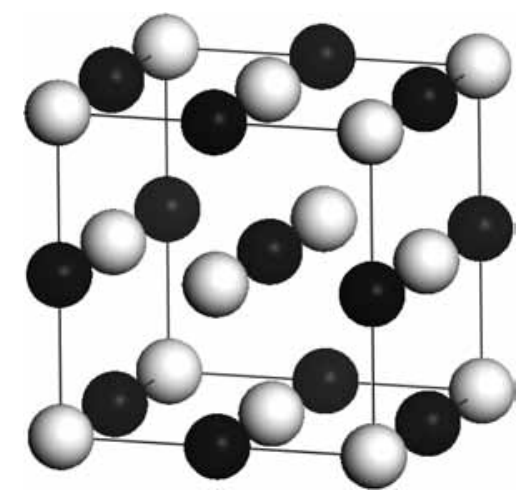

図 1 金属窒化物 $\mathrm{NaCl}$ 型構造の計算モデル 
ネルギーを算出した。単結晶 $\mathrm{CrN}$ を例として, 表面エネル ギーの算出法を説明する。

(1)構造最適化により得られた計算セルから (100), (110)面 を切り出し，その表面上に厚さ $10 \AA$ 以上の真空スラブ を付加して, 数原子からなる表面モデルを作成する。 図 2 に CrN (100)表面モデルを示す。

（2）（100）あるいは(110) 表面モデルおよび同一個数の原子 を含むバルクモデルの全エネルギーを計算する。

（3）全エネルギーの值と表面積から, 式(6)を用いて表面エ ネルギー $E_{s}$ を算出する。

$E_{s}=\frac{\left(E_{\text {surf }}-E_{\text {bulk }}\right)}{S}$

ここで， $E_{\text {surf }}$ は(100)表面あるいは(110) 表面モデルの全エネ ルギー, $E_{b u l k}$ はバルクモデルの全エネルギー, $S$ はモデルに おける(100)面あるいは(110)面の表面積である。

CrN (100)表面について，図 2 に示す表面モデルと，その 半分の表面積を有する表面モデルで計算した表面エネルギー の差は $0.09 \mathrm{~J} / \mathrm{m}^{2}$ であった。それ故，表面エネルギーの大小 関係の比較において，少なくとも $0.09 \mathrm{~J} / \mathrm{m}^{2}$ 以内の差は有意 ではない。本計算により得られた TiN (100) 表面と (110)表 面の表面エネルギーは $1.68 \mathrm{~J} / \mathrm{m}^{2}$ と $3.18 \mathrm{~J} / \mathrm{m}^{2}$ であった。これら の值は表面エネルギーの文献值である $1.75 \mathrm{~J} / \mathrm{m}^{2}$ と $3.13 \mathrm{~J} / \mathrm{m}^{2}$ とよく一致している ${ }^{34)}$ 。

表面エネルギーが小さい場合，面内での原子間結合力が強 く，安定な表面を形成している。すなわち，表面において， 成形物との相互作用が小さいと考えられる。それゆえ, 表面 エネルギーの值が低いほど，成形物との離型性が高いと判断 できる。

図 3 に各金属窒化物における (100) 表面と (110) 表面の表面 エネルギーの計算值を示す。これより，すべての金属窒化物 において，表面エネルギーは(100) 表面の方が(110)表面より も低い值であることがわかる。 $\mathrm{NaCl}$ 型単結晶では，（100)表 面における原子数密度が最も高い。それゆえ, 表面に露出し

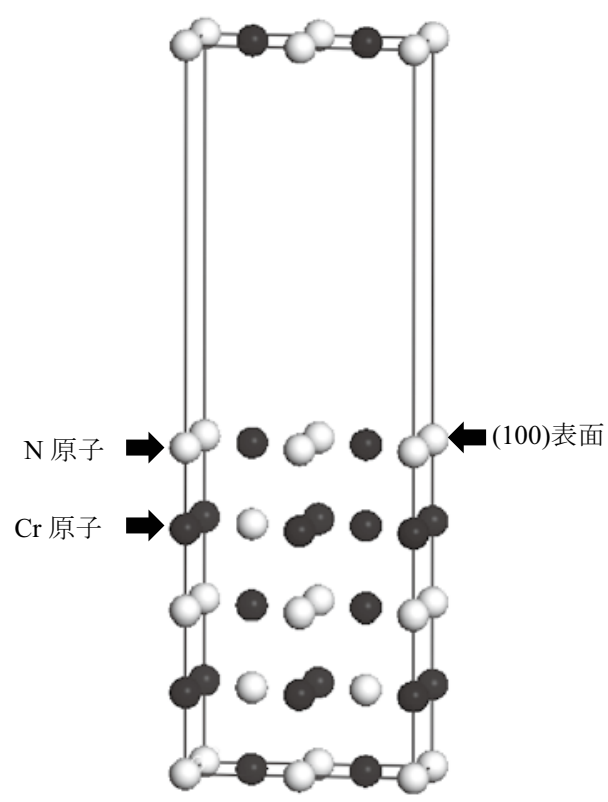

図 $2 \mathrm{CrN}(100)$ 表面の計算モデル
た未結合手 (ダングリングボンド) 数の面積密度が(110) 表面 よりも(100)表面の方が少ないことが, 各金属窒化物におい て(100) 表面の表面エネルギーが(110) 表面より低い理由と考 えられる。なお，（111）表面およびそれより高指数面につい ては計算していないが, 高指数面になるほど未結合手の面積 密度が高くなることから, $\mathrm{NaCl}$ 型金属窒化物において (100) 表面よりも表面エネルギーが低い結晶表面は存在しないと考 えられる。また，計算した金属窒化物において，一般的に離 型性が高いといわれている $\mathrm{CrN}$ の表面エネルギーが最も低 い結果であった。なお，他の金属窒化物 (100)表面の間では, 表面エネルギーの值に有意な差はみられなかった。

図 4 に(100) 表面における金属原子と $\mathrm{N}$ 原子の有効電荷を 示す。 $\mathrm{CrN}(100)$ の表面エネルギーが最も低かった理由として, $\mathrm{Cr}$ 原子の正の有効電荷と $\mathrm{N}$ 原子の負の有効電荷がいずれも 小さいことに起因して両原子間のイオン結合力が小さく，そ のため表面を形成する際に $\mathrm{Cr}$ 原子と $\mathrm{N}$ 原子の結合を容易に 切ることが可能であることが考えられる。

$\mathrm{CrN}$ は金型コーティング膜として実用されている。本計算 結果は, $\mathrm{CrN}$ の (100) 配向性を高めることで, 離型性がさら に向上する可能性を示している。

\section{4.まとめ}

本論文では，まず，材料を原子や電子の集合体として扱う

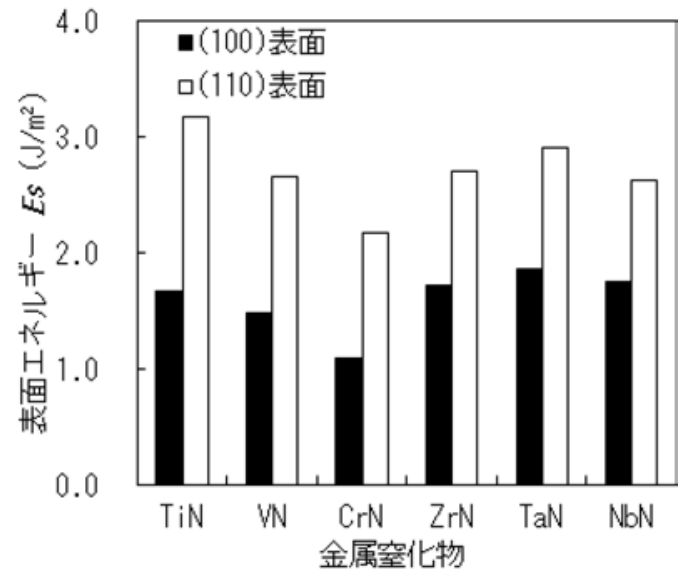

図 3 金属窒化物 (100) 表面と (110) 表面の表面エネルギー

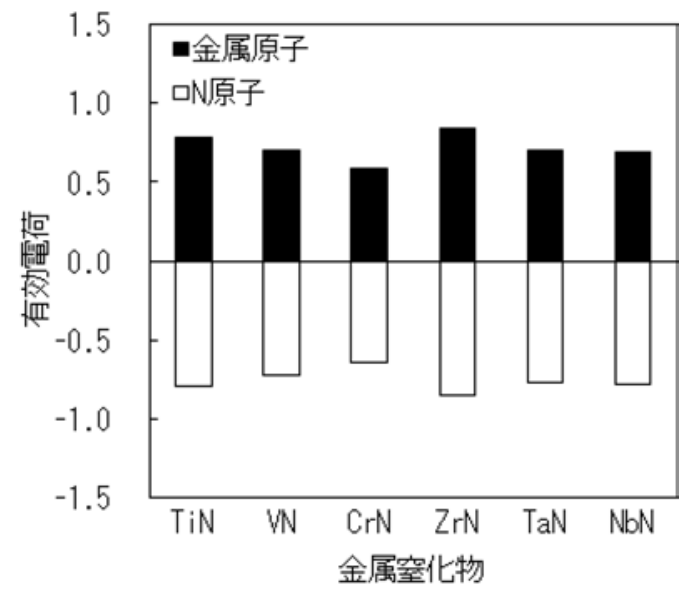

図 4 金属窒化物 (100)表面の金属原子と $\mathrm{N}$ 原子の有効電荷 
分子シミュレーション法を紹介したうえで，材料開発におけ るその重要性を述べた。

さらに，金型コーティング膜の離型性予測を目的として, 第一原理計算を用いて金属窒化物の表面エネルギーを計算し た内容を紹介した。具体的には，これまで実験值が報告され ていない $\mathrm{NaCl}$ 型窒化物の表面エネルギーについて，第一原 理計算法を用いて算出した。 $\mathrm{TiN}, \mathrm{VN}, \mathrm{CrN}, \mathrm{ZrN}, \mathrm{TaN}$, $\mathrm{NbN}$ (100) と（110）の表面エネルギーを計算したが，いずれ の金属窒化物でも (100)の方が(110)よりも表面エネルギーが 低いことがわかった。その中でも， CrN (100)の表面エネル ギーが最小であった。

$\mathrm{CrN}$ は金型コーティング膜として実用されている。本計算 結果は, $\mathrm{CrN}$ の (100)配向性を高めることで, 離型性がさら に向上する可能性を示している。

(Received August 30, 2013)

\section{文献}

1）日本表面科学会; 計算機シミュレーションと分析データ解析, p.3, (丸善, 2008)

2 ）富田佳宏; 日本ゴム協会誌, 82, 464 (2009).

3 ）下川智嗣, 平本知之, 喜成年泰, 新宅救徳; 材料, 56, 1068 (2007).

4) 日本表面科学会; 計算機シミュレーションと分析データ解析, p.71，(丸善, 2008).

5 ）豊島沙織, 川村隆明; 表面科学, 23, 431 (2002).

6 ) 影島博之; 応用物理, 75, 1258 (2006).

7 ) 吳 東和, 宮崎 剛, 大野隆央; 表面科学, 26,604 (2005).

8 ) 渡会雅敏, 中村 淳, 名取晃子; 表面科学, 24, 550 (2003)

9 ) 東 健司; 軽金属, 60, 411 (2010).

10）東 健司;軽金属,60, 458 (2010).

11）上辻靖智, 野村英太, 小池一歩, 佐々誠彦, 井上正崇, 矢野満明; 材 料, $\mathbf{5 8}, 243$ (2009).

12）笠井秀明, 赤井久純, 吉田 博; 計算機マテリアルデザイン入門, (大阪大学出版会, 2005)

13) P. Hohenberg and W. Kohn ; Phys. Rev., 136, B864 (1964).

14) W. Kohn and L. Sham ; Phys. Rev., 140, A1133 (1965).

15）前田豊一; 材料試験技術, 54, 81 (2009).
16）白木尚人, 関 宏友, 浜村尚樹, 鈴木信夫, 新国哲夫 ; 材料試験技 術, 54, 86 (2009)

17）神田一隆, 嶋田安広, 蓮井俊介; 福井工業大学研究紀要, 39, 115 (2009)

18）仁平宣弘; 溶接学会誌, 63, 269 (1994).

19）市村博司; セラミックス, 24, 433 (1989).

20）菅沼幹裕, 行木啓記, 吉元昭二, 福原 徹; 愛知県産業技術研究所 研究報告, 6, 10 (2007).

21）服部幸司, 松尾 博; 金属, 58,68 (1988).

22）市村博司; 資材と素材, 105, 159 (1989).

23）市村博司, 池永 勝; プラズマプロセスによる薄膜の基礎と応 用, p. 115 (日刊工業新聞社, 2005).

24) T. Chihi, S. Boucetta and D. Maouche ; Acta Physica Polonica A, 116, 1085 (2009).

25) D. Maouche, L. Louail, P. Ruterana and M. Maamache ; Computational Materials Science, 44, 347 (2008).

26）土屋文隆,鈴木秀人; 表面技術, 58, 130 (2007).

27）北田良二, 岡田 晃, 宇野義幸; 型技術, 25,37 (2010)

28）山本洋之, 大久保雄司, 小川一文, 内海邦広; 成形加工, 21,38 (2009)

29）山本洋之, 大久保雄司, 小川一文; 成形加工, 22, 104 (2010).

30）佐々木哲夫, 小林義和, 白井健二 ; 型技術, 17, 62 (2002).

31）上鴆桂二; 日本ゴム協会誌, 82,300 (2009).

32) 水本清文; 日本ゴム協会誌, 82,323 (2009).

33）國次真輔, 西田典秀, 後藤雅宏 ; 表面技術, 55, 214 (2004).

34) M. Mario and V. Milman ; Phys. Rev. B, 62, 2899 (2000).

35) The CASTEP code is available from Accelrys Software Inc.

36) J. Pflüger, J. Fink, W. Weber and K. P. Bohnen ; Phys. Rev., B, 301155 (1984)

37) A. Nørlund ; Acta Chem. Scand., A29, 563 (1975).

38) S. Hosoya, T. Yamagishi and M. Tokonami ; J. Phys. Soc. Jpn., 24, 363 (1968)

39) N. Pessall, R. E. Gold and H. A. Johansen; J. Phy. Chem. Solids, 29, 19 (1968).

40) T. Mashimo, S. Tashiro, T. Toya, M. Nishida, H. Yamazaki, S. Yamaya, K. Oh-ishi and Y. Syono ; J. Mater. Sci., 28, 3439 (1993).

41) N. Schönberg; Acta Chem. Scand., 8, 213 (1954). 